\title{
Ventilation in chronic heart failure: effects of physical training
}

\author{
P Davey, T Meyer, A Coats, S Adamopoulos, B Casadei, J Conway, P Sleight
}

\begin{abstract}
Objective-To assess the effects of exercise training on ventilatory function in chronic heart failure.

Design-Observer blinded random allocation crossover training and detraining trial.
\end{abstract}

Setting-Assessment in hospital based clinical laboratory; training home based.

Patients-22 patients with chronic heart failure (New York Heart Association (NYHA) class II or III) recruited from a tertiary referral centre. All finished the study.

Intervention-Bicycle ergometer exercise for $\mathbf{2 0}$ minutes a day, five days a week for eight weeks at $70 \%-80 \%$ of maximum heart rate.

Main outcome measures-Exercise capacity on graded incremental exercise test, minute ventilation, oxygen consumption and carbon dioxide output.

Results-Peak work load increased from $96 \mathrm{~W}$ to $112 \mathrm{~W}$ and peak oxygen consumption from $14.1 \mathrm{ml} / \mathrm{kg} / \mathrm{min}$ to $15.4 \mathrm{ml} / \mathrm{kg} / \mathrm{min}(p<0.01)$. At submaximal workloads carbon dioxide excretion $\left(\mathrm{VCO}_{2}\right)$ and minute ventilation (Vi) decreased significantly $(p<0.05)$ though oxygen consumption was unchanged. The relation between $V i$ and carbon dioxide excretion changed: the slope of the $\mathrm{Vi}$ to $\mathrm{VCO}_{2}$ plot decreased from 38.6 to $35 \cdot 3$, indicating an improvement in overall ventilary efficiency. The instantaneous carbon dioxide ventilatory equivalent $\left(\mathrm{Vi} / \mathbf{V C O}_{2}\right)$ decreased at submaximal workloads, and reached a lower mimimum value after training, indicating that optimum ventilatory performance improved. The exercise capacity of patients was related to the optimum ventilatory performance. It is suggested that this may in part be mediated through changes in skeletal muscles.

Conclusion-Exercise training reduces the ventilatory abnormalities in chronic heart failure; thus some of these changes may be due to physical deconditioning.

\section{(Br Heart J 1992;68:473-7)}

Reduced capacity to exercise in patients with chronic stable heart failure is often associated with breathlessness that may be defined as either a sense of laboured respiration or increased breathing frequency volume. ${ }^{12}$ The origin of this symptom is multifactorial, ${ }^{3}$ but increased ventilation plays a part. Haemodynamic abnormalities are only poorly correlated with the intensity of dyspnoea. ${ }^{4}$ Other factors, such as the changes in skeletal muscles that cause the early start of acidosis during exercise ${ }^{5}$ (as detected by magnetic resonance spectroscopy ${ }^{6}$ ) may increase ventilation during exercise and thus contribute to dyspnoea. Wasting, weakness, and early tiredness, ${ }^{7}$ particularly of the leg muscles, increase the perception of the severity of exercise and through changes in respiratory reflexes may increase breathlessness. Drugs that reduce exercise dyspnoea in chronic heart failure often do so four to eight weeks after the acute haemodynamic improvement has occurred, and it may be that changes in some of the peripheral abnormalities of heart failure must take place first. We hypothesised that these abnormalities may be major limiting factors in their own right, ${ }^{6}$ and that if the function of skeletal muscle were improved through a programme of physical training, increases in capacity to work and ventilatory function might follow. ${ }^{8}$ We therefore evaluated the effect that a home based programme of physical training had on the ventilatory performance during exercise in patients with chronic stable heart failure.

\section{Methods}

The study was approved by the local ethics committee. Twenty two patients with chronic heart failure participated in the study (seven had participated in an earlier training study ${ }^{8}$ ). They were all men, mean age 64 (range 54-74) years. The aetiology was ischaemic heart disease in 19, dilated cardiomyopathy in two, and valvar disease in one. Thirteen patients were in New York Heart Association (NYHA) class II, and the rest were in class III. No patient had angina as a limiting symptom. Left ventricular ejection fraction by radionuclide ventriculography was mean (SD) $22(8) \%$. All patients had been stable for at least three months before the study. Significant pulmonary disease was excluded clinically and by chest $x$ ray films. All patients were taking diuretics, a mean frusemide equivalent dose of 84 (SD 21) mg. Nine were taking an angiotensin converting enzyme inhibitor. 
Table 1 The effect of training on capacity to work and peak $\mathrm{VO}_{2}$ (mean (SD))

\begin{tabular}{|c|c|c|c|c|}
\hline & Detrained & Trained & p Value & Increase \\
\hline $\begin{array}{l}\text { Exercise time (min) } \\
\text { Total external work (kJ) } \\
\text { Peak external work (W) } \\
\text { Peak } \mathrm{VO}_{2}(\mathrm{ml} / \mathrm{kg} / \mathrm{min})\end{array}$ & $\begin{array}{lc}14 & 3 \\
49 \cdot 6 & 17 \cdot 6 \\
96 & 22 \\
14 \cdot 1 & 2 \cdot 8\end{array}$ & $\begin{array}{cc}16 & 3 \cdot 4 \\
66 \cdot 4 & 23 \cdot 8 \\
112 & 20 \\
15 \cdot 4 & 2 \cdot 8\end{array}$ & $\begin{array}{l}0.001 \\
0.001 \\
0.001 \\
0.01\end{array}$ & $\begin{array}{r}14 \% \\
33 \% \\
16 \% \\
9 \%\end{array}$ \\
\hline
\end{tabular}

\section{STUDY DESIGN}

Patients were entered in random order to a training or detraining period of a cross over study. After three baseline exercise tests, designed to ensure reproducibility and familiarity with the laboratory, patients were randomly assigned to either study period, with assessment at the end of each period. For training, patients were lent a Tunturi professional cycle ergometer for use five days each week for eight weeks. These cycle ergometers were used at home. Patients monitored their own heart rates during exercise with an electrocardiographically based pulse monitor (Micro Sports Lab Computer, Triadcolour, London). Patients warmed up with the resistance set at $25 \mathrm{~W}$ for one minute, and then increased the setting until the heart rate was $70 \%-80 \%$ of their previously determined maximum (thus automatically increasing the workload as training developed). After 20 minutes at this higher setting, patients cooled down for one minute at $25 \mathrm{~W}$. Compliance was assessed by a revolution counter and expressed as a percentage of revolutions achieved divided by revolutions expected. In the detraining period, the exercise bicycle was removed, and the patient instructed to avoid all exercise that induced dyspnoea or fatigue. Resting left ventricular ejection fraction was measured by radionuclide ventriculography.

\section{EXERCISE TESTS}

Exercise capacity and respiratory performance were measured on a Tunturi bicycle ergometer in four minute $25 \mathrm{~W}$ incremental stages to exhaustion. Tests were performed at the same time of day, after an overnight fast, and before medication had been taken. Gas analysis ${ }^{910}$ was performed by measuring inspired airflow (Harvard instruments dry gas meter for minute ventilation) and expiratory oxygen and carbon dioxide concentration by gas meter (570A and PA404, Servomex, Crowborough, Sussex). The instruments were calibrated against gas mixtures of known concentration at the start of each exercise test. Data from the dry gas meter and the gas analysers were transmitted on line to a Hewlett-Packard personal computer and converted, with standard formulas, to gas volumes at standard temperature and pressure. Breathing frequency was measured for the first 12 patients in the programme with a thermistor positioned proximally in the expiratory air pipe. Heart rate was recorded from the electrocardiograph and blood pressure was measured by a sphygmomanometer at the end of each four minute stage and at peak exercise.

\section{STATISTICS}

Patients were assessed by observers who were blind to their training state. Data were expressed as mean (SD). Results were compared before and after training with the paired Student's $t$ test. The slope of minute ventilation to minute carbon dioxide excretion was found with a least squares fitting algorithm. Significance was accepted at the 5\% level. Figures have standard error bars.

\section{Results}

The effects of training on exercise performance of seven of these 22 patients has previously been reported. ${ }^{8}$ Baseline test did not differ from those obtained after detraining, and no carry over effects were detected. Training (table 1) produced a significant improvement in exercise capacity. At matched submaximal work loads there was no significant change in oxygen consumption (table 2), but the overall oxygen consumption for the exercise test compared with the total amount of external work performed fell from $0.243(0.051) \mathrm{ml}$ oxygen per Joule external work to $0.221(0.043) \mathrm{ml}$ oxygen per Joule external work $(p<0.05)$.

\section{VENTILATORY PERFORMANCE}

Minute ventilation showed highly significant decreases at submaximal workloads, but no change at peak exercise (table 3 ). An inverse correlation between peak minute ventilation and severity of heart failure has been reported in severe chronic heart failure, ${ }^{11}$ but we found no such correlation within the group. There was a non-significant trend for the tidal volume to increase earlier and to a greater extent during exercise, with severity of disease.

\section{GAS EXCHANGE}

Carbon dioxide excretion decreased significantly at 50,75 , and $125 \mathrm{~W}$ submaximal workloads (table 2) and tended to decrease at other workloads. At peak exercise there was a significant increase in minute carbon dioxide excretion, with no significant change in minute ventilation. Carbon dioxide excretion is highly

Table 2 The effect of training on submaximal and peak oxygen consumption and carbon dioxide excretion. Data is in $\mathrm{ml} / \mathrm{kg} / \min (\operatorname{mean}(S D))$

\begin{tabular}{|c|c|c|c|c|c|c|}
\hline Load & $\begin{array}{l}\mathrm{VO}_{2} \\
\text { Detrained }\end{array}$ & $\begin{array}{l}\mathrm{VO}_{2} \\
\text { Trained }\end{array}$ & p Value & $\begin{array}{l}\mathrm{V} \mathrm{CO}_{2} \\
\text { Detrained }\end{array}$ & $\begin{array}{l}\mathrm{V} \mathrm{CO}_{2} \\
\text { Trained }\end{array}$ & p Value \\
\hline $\begin{array}{l}\text { Rest } \\
25 W \\
50 W \\
75 W \\
100 W \\
125 W \\
\text { Pcak }\end{array}$ & $\begin{array}{rr}3.47 & 0.8 \\
6.08 & 1.1 \\
8.98 & 1.5 \\
11.5 & 2.1 \\
14.0 & 2.3 \\
15.7 & 3.2 \\
14.1 & 2.8\end{array}$ & $\begin{array}{rr}3.4 & 0.5 \\
6.13 & 0.8 \\
8.71 & 1.3 \\
11.2 & 1.5 \\
14.4 & 2.3 \\
15.6 & 2.4 \\
15.4 & 2.8\end{array}$ & $\begin{array}{l}\text { NS } \\
\text { NS } \\
\text { NS } \\
\text { NS } \\
\text { NS } \\
\text { NS } \\
0.01\end{array}$ & $\begin{array}{cr}3 & 0.5 \\
5.2 & 0.9 \\
8 & 1.4 \\
11.3 & 1.9 \\
14.8 & 1.9 \\
16.2 & 2.9 \\
14.9 & 2.8\end{array}$ & $\begin{array}{rl}2.9 & 0.6 \\
4.9 & 0.8 \\
7.3 & 1.1 \\
10.4 & 1.5 \\
14.4 & 2.4 \\
13.4 & 2.7 \\
16.3 & 3.3\end{array}$ & $\begin{array}{l}\text { NS } \\
\text { NS } \\
0.02 \\
0.03 \\
\text { NS } \\
0.01 \\
0.01\end{array}$ \\
\hline
\end{tabular}


Table 3 Ventilation at matched submaximal and peak workloads (l/min)

\begin{tabular}{lllll}
\hline Load & Detrained & Trained & $p$ Value & $n$ \\
\hline Rest & 11.32 & 10.51 .9 & 0.05 & 22 \\
$25 \mathrm{~W}$ & 16.53 .9 & 15.9 & 0.05 & 22 \\
$50 \mathrm{~W}$ & 23.46 .8 & 20.94 .7 & 0.005 & 22 \\
$75 \mathrm{~W}$ & 32.17 & 28.66 .2 & 0.005 & 21 \\
$100 \mathrm{~W}$ & 41.88 .9 & 38.17 .6 & 0.05 & 14 \\
$125 \mathrm{~W}$ & 416.1 & 38.88 .6 & NS & 5 \\
Peak & $47.89 \cdot 2$ & 48.59 .6 & NS & 22 \\
\hline
\end{tabular}

dependent on effective minute alveolar ventilation, and so to assess whether the changes in minute carbon dioxide excretion were related to the changes in minute ventilation, we plotted the change in minute carbon dioxide excretion that training induced against the reduction in minute ventilation at each minute of each workload for each patient and found that for all subjects there was a highly significant correlation (mean correlation $r=0.88(0.11)$ $(\mathrm{p}<0.01)$.

The time taken to reach a respiratory quotient $\left(\mathrm{RQ}=\mathrm{VCO}_{2} / \mathrm{Vo}_{2}\right)$ of unity increased significantly with training from $10.9(2.9)$ minutes to $13.7(2.8)$ minutes, $p<0.01$, reflecting a delay in the start of anaerobic metabolism. At submaximal workloads, although not at rest or at peak workloads, the respiratory quotient was reduced significantly (fig 1).

The relation between minute ventilation and minute carbon dioxide excretion, which has been reported to be steeper in those with heart failure $^{11}$ was studied. In each patient the correlation between $\mathrm{Vi}$ and carbon dioxide excretion, found by simple regression analysis, exceeded 0.9 . The slope of the $\mathrm{Vi}-\mathrm{VCO}_{2}$ line decreased from $38.6(11.0)$ to $35.5(8.4)$, $\mathrm{p}<0.01(\mathrm{ml}$ of ventilation $/ \mathrm{ml}$ of carbon dioxide excretion). There was a significant inverse relation between the steepness of the $\mathrm{Vi}-\mathrm{VCO}_{2}$ slope and the capacity to exercise (detrained $r=0.64, \mathrm{p}<0.001$, trained $r=$ $0.56, \mathrm{p}<0.01$ ), as previously described. ${ }^{3}$

Whereas the relation between minute ventilation and carbon dioxide production is linear, the relation between the ventilatory carbon dioxide equivalent (minute ventilation/carbon dioxide excretion) and exercise time is not. Each patient showed the same general pattern (fig 2). At rest the $\mathrm{Vi} / \mathrm{VCO}_{2}$ value was comparatively high. As exercise progressed the

Figure 1 Effect of training on respiratory quotient: rest, matched submaximal and peak workloads.

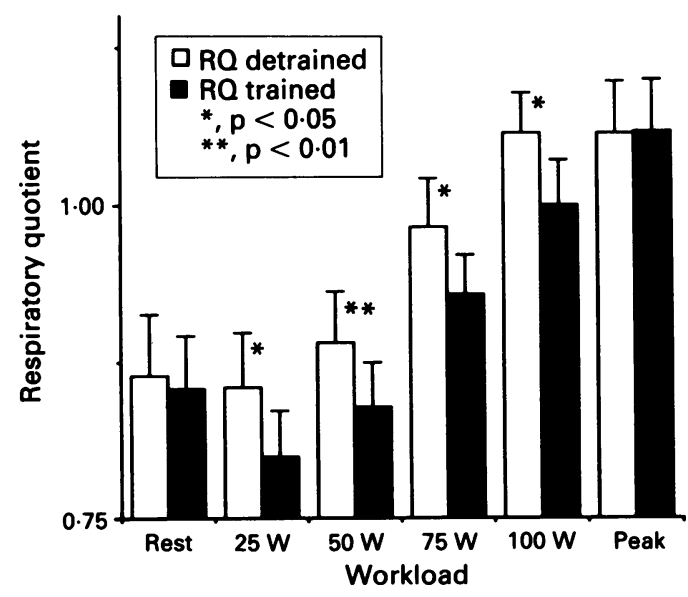

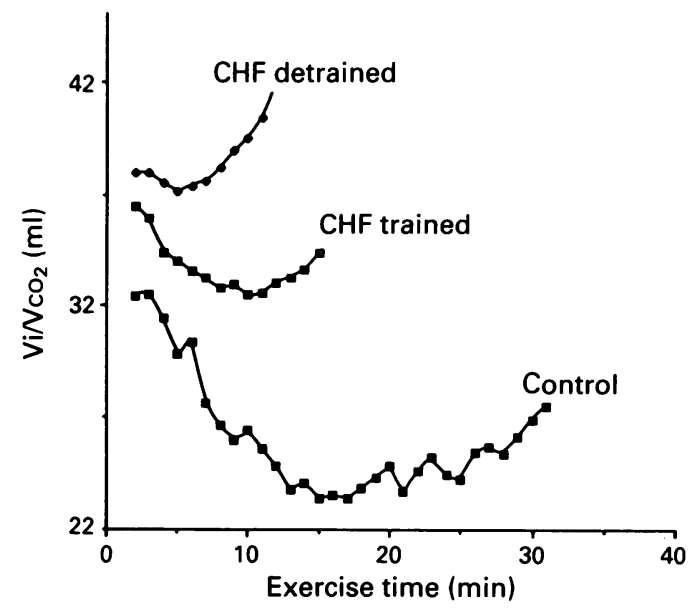

Figure 2 Carbon dioxide ventilatory equivalent ( $\mathrm{Vi} / \mathrm{VCO}_{2}$ ) plotted against exercise time for one patient before and after training ( $C H F$ detrained, $C H F$ trained). The normal control in this case was a healthy untrained 45 year old man.

$\mathrm{Vi} / \mathrm{VCO}_{2}$ value progressively decreased until a trough point was reached. This point was established by taking the minimum numerical value of $\mathrm{Vi} / \mathrm{VCO}_{2}$. If there were more than two points with an identical minimum value, the middle one of the range was taken. With increasingly heavy workloads the carbon dioxide ventilatory equivalent increased, continuing to do so until exercise stopped. The trough point, which may be regarded as that part of the exercise test where patients require the least minute ventilation per unit of carbon dioxide excretion, was reached before training at $65.8(13.5) \%$ of peak work load, and after training at $69 \cdot 6(13) \%$ of peak work load (NS). This point of maximum ventilatory efficiency with respect to carbon dioxide excretion correlated well with total exercise time before and after training (fig 3). The start and trough point were both affected by the training process (fig 4), both being lowered, and the time taken to reach the trough point was significantly delayed by training, from 7.9 (3) minutes to $10 \cdot 1$ (3.3) minutes. The steeper increase in minute ventilation at higher workloads (comparing the difference between the trough with maximum $\mathrm{Vi} / \mathrm{VCO}_{2}$ ), unlike the linear

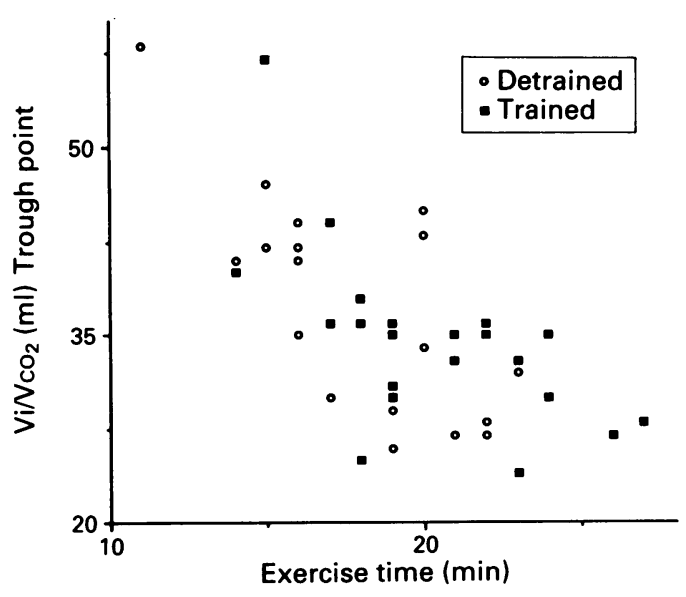

Figure 3 Relation between minimum point in the Vi) $\mathrm{COO}_{2}$ curve and capacity to exercise. 
Figure 4 Effect of exercise and training on carbon dioxide ventilatory equivalent $\left(\mathrm{Vi} / \mathrm{VCO}_{2}\right)$.

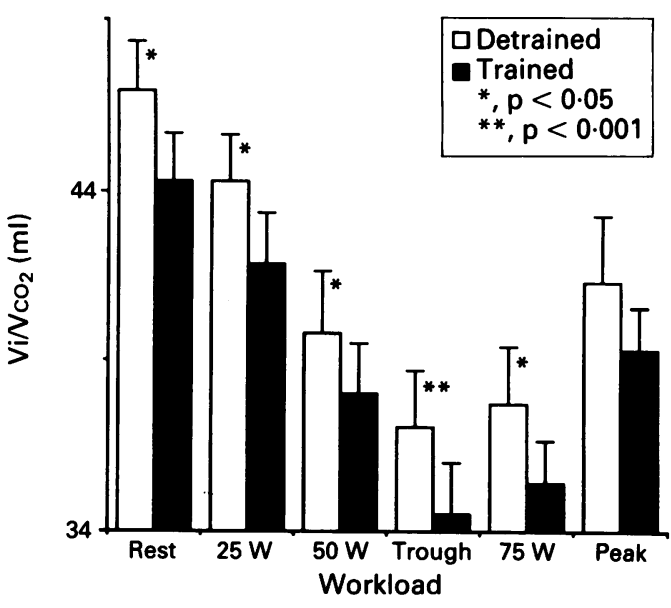

increase in minute ventilation at lower workloads, did not correlate with any measure of functional capacity.

\section{Discussion}

Short periods of physical training increase exercise capacity in patients with chronic heart failure. ${ }^{812-16}$ With a modest home based programme of physical exercise our subjects showed an increase in capacity to work. Peak oxygen consumption, however, underestimates the degree of symptomatic improvement as much benefit is in the improved capacity to endure submaximal work. Our results show a $33 \%$ increase in total external work performed, with only a rather more modest $9 \%$ increase in peak oxygen consumption. More intensive training programs can increase submaximum (2/3 of peak) workload endurance by up to $52 \% .13$

The mechanism of the increased work capacity may lie partially in the incomplete reversal of depressed peak cardiac output and raised peripheral resistance of chronic heart failure patients. ${ }^{1718}$ Training may increase blood supply to the leg, and partly reverse some of the skeletal muscle changes caused by chronic heart failure ${ }^{619-21}$ by, for example, increasing energy producing enzymes, particularly fatty acid oxidative enzymes, and switching to a more efficient type of fibre distribution. An increase in the fatty acid contribution to energy production will lessen the respiratory quotient $\left(\mathrm{VCO}_{2} / \mathrm{Vo}_{2}\right)$, and greater delivery and extraction of oxygen in the legs will delay anaerobic glycolysis.

Decreased carbon dioxide production and a later start of acidosis will both decrease submaximal minute ventilation. We have shown that a very close relation exists between the reductions in minute ventilation and in carbon dioxide excretion that training induces. This relation in itself does not necessarily imply causality due to the speed with which alveolar capillary carbon dioxide equilibrates with alveolar gas but as the carbon dioxide buffering capacity of the body is small compared with the carbon dioxide flux, and respiratory acidosis does not occur (indeed, in chronic heart failure there is a tendency to arterial hypocapnia and alkalosis $^{12}$ ), this suggests that the reduction in minute ventilation is mainly metabolically mediated.

The $8.5 \%$ reduction in the slope of the $\mathrm{Vi}$ to $\mathrm{VCO}_{2}$ relation, however, which is raised in heart failure $^{311}$ suggests that ventilation is decreased over and above the reduction in carbon dioxide production that is ventilatory efficiency is increased. This may be due to a reduction in pulmonary dead space, either due to an increase in tidal volume (though this is small), or to improved pulmonary haemodynamics. Overall pulmonary haemodynamics have not been found to change in previous training studies, though this does not preclude beneficial changes in the local balance between perfusion and ventilation. Alternatively, changes in the control of ventilation (possibly through changes in chemo and mechanoreceptors in the legs), may have contributed to the reduction in ventilation.

The relation between carbon dioxide excretion and minute ventilation was looked at in more detail, with the carbon dioxide ventilatory equivalent $\left(\mathrm{Vi} / \mathrm{VCO}_{2}\right)$ plotted against workload. This curve gives the minute ventilation at any workload once it has been standardised for carbon dioxide production and so it represents ventilatory efficiency. In normal subjects, however, this is also correlated with chemoreceptor responsiveness to hypoxia and hypercapnia. ${ }^{22}$ The point of maximum ventilatory efficiency was improved and delayed by the training process. The good correlation of this point with total exercise time suggests that optimum ventilatory performance is related in a meaningful way to capacity exercise in heart failure. The relation may be through pulmonary and systemic haemodynamics, chemoreceptor sensitivity, or skeletal muscle changes. This point of optimum ventilatory efficiency may be an objective method of assessing the efficacy of therapeutic interventions in the treatment of chronic heart failure.

It is often assumed that the $\mathrm{Vi} / \mathrm{VCO}_{2}$ relation is close to linear, so that the slope of the line can describe its behaviour. Although the individual correlation coefficients of $\mathrm{Vi} v \mathrm{VCO}_{2}$ are high $(>0.9)$ this does not imply a straight line relation between the two. Figure 2 shows the relation is clearly not linear but turns up at the end so that we believe the plot of instantaneous $\mathrm{Vi} / \mathrm{VCO}_{2} v$ exercise time or load with its trough point gives more information than the conventional plot of $\mathrm{Vi} v \mathrm{VCO}_{2}$. This is supported by the better correlation between trough point $\mathrm{Vi} / \mathrm{VCO}_{2}$ and exercise time than between mean $\mathrm{Vi} / \mathrm{VCO}_{2}$ slope and exercise time.

In conclusion, we found that a short course of mild home based exercise training was effective in improving the exercise peformance of patients with NYHA class II and III stable chronic heart failure, improving peak exercise capacity, decreasing submaximal minute ventilation and carbon dioxide output, and improving ventilatory efficiency. It may be that some of these changes in chronic heart failure are the result of deconditioning rather than the heart failure itself. 
This study was supported in part by the British Heart Foundation.

1 Rubin SA, Brown HV. Ventilation and gas exchange during exercise in chronic heart failure. Ann Rev Respir Dis 1984; 129:63-4.

2 Sullivan MJ, Atwood JE, Myers J, et al. Increased exercise after digoxin administration in patients with chronic heart failure. J Am Coll Cardiol 1989;13:1138-43.

3 Buller NP, Poole-Wilson PA. Mechanism of the increased ventilatory response to exercise in patients with chronic ventilatory response to exercise in patient
heart failure. $B r$ Heart $J 1990 ; 63: 281-3$.

4 Franciosa JA, Leddy CL, Wilen M, Schwartz DE. Relation between hemodynamic and ventilatory responses in determining exercise capacity in severe congestive heart failure. Am J Cardiol 1984;53:127-34.

5 Higginnbotham MB, Morris KM, Conn EH, Coleman RE, Cobb FR. Determinants of variable exercise performance among patients with severe left ventricular dysfunction. Am J Cardiol 1983;51:52-60.

6 Massie B, Conway M, Yonge R, et al. Skeletal muscle metabolism in patients with congestive heart failure: relation to clinical severity and blood flow. Circulation 1987;76:1009-19.

7 Buller NP, Jones D, Poole-Wilson PA. Direct measurement of skeletal muscle fatigue in patients with chronic heart of skeletal muscle fatigue in pati
failure. $B r$ Heart $J$ 1991;65:20-4.

8 Coats AJS, Adamopoulos S, Meyer TE, Conway J, Sleight $P$. Effects of physical training in chronic heart failure. Lancet 1990;335:63-6.

9 Janicki JS, Weber KT, Mcelroy PA. Use of the cardiopulmonary exercise test to evaluate the patient with chronic heart failure. Eur Heart $J$ 1988;9 (suppl):55-8.

10 Lipkin DP. The role of exercise testing in chronic heart failure. Br Heart J 1987;58:559-66.

11 Weber KT, Kinasewitz GT, Janicki JS, Fishman AP. Oxygen utilisation and ventilation during exercise in patients with chronic cardiac failure. Circulation 1982;65:1213-23.

12 Sullivan MJ, Cobb FR. The anaerobic threshold in chronic heart failure. Relation to blood lactate, ventilatory basis, reproducibility, and response to exercise training. Circulation 1990;81 (suppl 2):47-58.

13 Sullivan MJ, Higginnbotham MB, Cobb FR. Exercise training in patients with severe left ventricular dysfunction. Circulation 1988;78:506-15.

14 Letac B, Cribier A, Desplanches JF. A study of left ventricular function in coronary patients before and after physical training. Circulation 1977;56:375-8.

15 Lee AP, Ice R, Blessey R, Sanmarco ME. Long term effects of physical training on coronary patients with impaired of physical training on coronary patients with impai

16 Conn EH, Williams RS, Wallace AG. Exercise responses before and after physical conditioning in patients with severely depressed left ventricular function. Am J Cardiol 1982;49:296-300.

17 Wilson JR, Wiener DH, Fink LI, Ferraro N. Vasodilatory behaviour of skeletal muscle arterioles in patients with nonedematous chronic heart failure. Circulation 1986; 74:775-9.

18 Zelis R, Flaim SF. Alterations in vasomotor tone in congestive heart failure. Prog Cardiovasc 1982;29:437-59.

19 Ivy JL, Withers RT, Van Handel PJ, Elger PH, Costill DL. Muscle respiratory capacity and fibre type as determinants Muscle respiratory capacity and fibre type as determinan
of the lactate threshold. $J$ Appl Physiol 1980;48:523-7.

20 Matsumura N, Nishijima H, Kojima S, Hashimoto F, Minami M, Yasuda H. Determination of anaerobic threshold for assessment of functional state in patients with chronic heart failure. Circulation 1983;68:360-7.

21 Sullivan MJ, Green HJ, Cobb FR. Skeletal muscle biochemistry and histology in ambulatory patients with longterm heart failure. Circulation 1990;81:518-27.

22 Martin BJ, Weil JV, Sparks KE, McCullough RE, Grover RF. Exercise ventilation correlates positively with ventilatory chemoresponsiveness. J Appl Physiol 1991; 45:557-64. 